\title{
College Culture and Student Satisfaction
}

\author{
Raju Uprety* and Sabina Baniya Chhetri \\ Kathmandu University School of Management, Lalitpur, Nepal
}

\begin{abstract}
This study examines the relationship between college culture and student satisfaction. It also examines the order of strength of relationship of college culture dimensions as perceived by students with student satisfaction. The study was conducted among 251 BBA students of various colleges located within Kathmandu and Lalitpur districts of Nepal using Denison Organizational Culture Survey Model. We measured student satisfaction using the questionnaire adopted from Hartman and Schmidt (1995) and Silva and Fernandes (2012). Our results indicated that college culture dimensions involvement, adaptability, and consistency - related significantly to student satisfaction and the strength of relationship followed the order: involvement, adaptability and consistency.
\end{abstract}

Keywords: College culture, student satisfaction, BBA program, dimensions of college culture, organizational culture

\section{Introduction}

In today's competitive academic environment, delivery of high quality educational services and satisfied customers can be viewed as critical for successful existence of any higher education institutions. They compete among each other to attract potential students for different programs. They also need to enhance students' experience throughout their study period to further promote the services the institutions offer. In this regard, Porter (1985) suggested that a competitive advantage exists when an organization maintains an edge over its rivals in retaining customers and in positioning itself to take advantage of environmental changes. Under these circumstances, successful service organizations realize the importance of carefully monitoring and managing customer satisfaction (Bitner, Booms, \& Mohr, 1994).

Satisfaction is an "overall customer attitude towards a service provider" (Levesque \& McDougull, 1996, p. 14). In case of higher education institution, a satisfied customer plays an important role in the promotion of that particular institution. When competition to attract and retain students exists, the success of education institutions comes from considering market forces, establishing competitive positioning and having resource advantage (Cameron \& Quinn, 1999). Cameron and Quinn further added that organizational culture as a key 
ingredient determines the success of educational institutions. Many researchers (e.g., Denison, 1990, Koter \& Heskett, 1992) found that a company's culture has a close link to its effectiveness. Many organizational scholars have recognized that organizational culture has a powerful effect on the performance and long-term effectiveness of organizations (Cameron \& Quinn, 1999; Deshpande \& Farley, 2004; Lund, 2003; Sin \& Tse, 2000). The importance of culture can be illustrated by the claim of Ouchi and Wilkins (1985) that "organizational performance cannot be adequately nor accurately understood without a comprehension of the culture of the organization" (p. 469).

In the last few years there has been a rapid increase in the number of colleges offering Bachelor in Business Administration (BBA) program in Nepal. These colleges are affiliated to Kathmandu University (KU), Tribhuvan University (TU), Pokhara University, Purbanchal University and some foreign universities. Similarly, a significant number of students are going to neighbouring and other foreign countries to attend the BBA program. Thus it has become a challenge for colleges within the country to retain and attract students in the BBA programs available in the country. If colleges can create an environment of satisfaction for students that usually results through culture, they can attract and retain students for their BBA programs. Moreover, students will have enriching learning experience only when they are satisfied with the college.

The major question that the present study tried to investigate is - which dimensions of college culture affect student satisfaction? From the perspective of organization theory, colleges are also a type of organization. As a corollary, generic dimensions of organization are also applicable to colleges. Thus, in the absence of dimensions of organizational culture developed in the context of Nepal, this study uses dimensions of organizational culture framework proposed by Denison and colleagues (Denison, 1990; Denison \& Mishra, 1995; Fey \& Denison, 2003). This framework conceptualizes organizational culture along four dimensions: involvement, consistency, adaptability, and mission. Involvement and consistency have their focus on dynamics of internal integration, while mission and adaptability focus on dynamics of external adaptation. These four dimensions are consistent with Schein's (1990) observation that culture is developed as an organization learns to cope with the dual problems of external adaptation and internal integration. This organizational culture framework is used by Ehtesham, Muhammad, and Muhammad (2011) to assess the culture of Institute of Information Technology, University of Pakistan. Some studies (e.g., Okun, Braver, \& Weir, 1990; Bentz, Klingensmith, \& Menne, 1970, as cited in Liu \& Jung, 1980) claimed that student satisfaction level is also affected by student specific characteristics like - gender, residency type and year in college. Similarly, in the context of Nepal too students' level of satisfaction may be affected by such student specific characteristics. Therefore, this study also tried to investigate - do levels of student satisfaction vary based on gender, residency type, year in college and university affiliation? Before going into these 
questions we first discuss some of the key concepts used, describe the conceptual framework, set the hypotheses, and discuss the methods adopted in carrying out this study.

\section{Organizational Culture}

Organizational culture is considered the heart of human resource management strategy because of its influence on individuals' attitude and outcomes such as commitment, satisfaction, retention, performance, etc. Therefore, no organization can remain unaffected by the changes that occur in organizational culture. This further enhances the roles of organizational culture in ensuring the organizational performance. Against this backdrop, an important question arises - how does understanding and improving organizational culture fit into the current climate of Nepali colleges offering the BBA programs.

Barney (1986) saw culture as a viable source of competitive advantage and stressed that culture must be valuable, rare and not easy to imitate for a company to sustain superior performance (as cited in Trice \& Beyer, 1993). In the early 1980s, researchers such as Ouchi (1981), Pascale and Athos (1981), Peters and Waterman (1982), Deal and Kennedy (1982), and Schein $(1980,1985,1990)$ contributed to the conceptualization of organizational culture in higher education (Cameron \& Quinn, 2006). In the early 1990s, Trice and Beyer bridged researchers' earlier work by describing some typologies of organizational culture based on the research studies from the 1970s and 1980s. West-Monyes (2012) mentioned that typologies proposed by Trice and Beyer became very useful in identifying a sample of common dominant ideologies by researchers rooted in levels of control, risk taking, regard for employees, levels of trust and balance between flexibility and control. It is interesting to note that the terms 'clans' and 'hierarchy' identified by Trice and Beyer to denote the types of organizational culture (which was later used by Cameron \& Quinn, 1999) were also used as early as 1978 by Ouchi and Jaeger.

According to Schein (1983), Sathe (1983), and Cameron and Quinn (2006), as organizations adapt and respond to their changing environment, they tend to develop a dominant organizational culture. West-Moynes (2012) argued that, given the evolving study of organizational culture, as depicted in the literature, it is increasingly clear that organizational culture cannot be considered passively. The external influences affecting post secondary institutions, such as funding, performance, accountability, and the ability to attract students is clearly the active forces that dominate organizational reputation and influence organizational sense of worth (West-Moynes, 2012). The work of Martin (1992) explained that culture in organizations is complex and theoretical in nature; however the work describes culture from three different perspectives: integration, differentiation and fragmentation. Martin's analysis assists in the understanding of each perspective, the limitations, and further provides scholarly insights into the complexity of the culture research (West-Moynes, 2012).

In the context of Nepal, dominant work culture is characterized by hierarchy orientation, authority orientation, status quo orientation, rule orientation, close in-group orientation and 
performance for patrimonial relationship (Pant 2000 as cited in Pant, 2007). In addition, Dangal (2005) stated that the culture of a particular society shapes the character of organizations in that society. Thus, the values and culture of a society, and of course people, largely influence the functioning of the organization. West-Monyes (2012) also stated that neither the distinguishing characteristics of each college's organizational culture are well understood, nor are the specific changes that could be implemented to achieve the desired culture outcome well defined. West-Monyes further added that it is very possible that a broad and liberal use of the term culture can be seen as contributing to the lack of understanding of the concept of culture, contributing to its ongoing abstractness and inhibiting formal assessment to determine the distinguishing cultural features of an organization.

\section{Customer Satisfaction}

Kotler and Clark (1987) defined satisfaction as a state felt by a person who has experienced performance or an outcome that fulfils his or her expectation. In terms of students, expectation may go as far as before the students even enter the higher education, suggesting that it is important to the researchers to determine first what the students expect before entering the universities (Palacio, Meneses, \& Perez, 2002). In contrary, Carey, Cambiano, and De Vore (2002) believed that satisfaction actually covers issues of students' perception and experiences during the college years. They considered student satisfaction as a match between what students expect while entering colleges, and perception and experiences they develop during the college years. While most studies on satisfaction focus on the perspective of customers, researchers are facing a problem of creating a standard definition for student satisfaction thus providing a need of customer satisfaction theory to be selected and modified so that it can explain the meaning of student satisfaction (Hom, 2002, as cited in Hasan et al., 2008). Similarly, William (2002) mentioned that even though it is arguable to view students as customers, but given the current atmosphere of higher education marketplace, there is a new moral prerogative that students have become "customers" and therefore can, as fee payers, reasonably demand that their views be heard and acted upon. Our study also considers students as "customers".

\section{College Culture and Student Satisfaction}

The future of higher education institutions depends on their ability to attract and retain students. In order to respond to the increasing demand of customers, higher education institutions need to identify the key factors that influence the satisfaction of the 'customers', thereby creating a competitive advantage (Silva \& Fernandes, 2012).

A prior study on home construction markets and automobile dealership has predicted relationship between organizational culture and customer satisfaction (Gillespie, Denison, Haaland, Smerek, \& Neale, 2008). Some Nepali studies (e.g., Shrestha, 2013; Thapa, 2011) have explored about Total Quality Management (TQM) in the education sector in Nepal. 
Thapa (2011) mentioned that TQM is a philosophy and system for continuously improving the services or products offered to customers. It is a management system for a customerfocused organization that involves all employees in the continual improvement of all aspects of the organization. Shrestha (2013) argued that TQM has limitations as it focuses only on satisfying customers' expectations, in this case, students' expectations. However, other stakeholders such as parents, employers, faculty members and general society also have expectations and play an important role in influencing the recipients in making choices of educational programs as well as institutions. Both Shrestha and Thapa in their studies have not examined the role of culture but related the concept of TQM with satisfying students. The culture of a higher education institution plays an important role in actual realization of the expectation with which students admit themselves to the institution and thus student satisfaction plays a role of influencer to other stakeholders.

Previous literature offers varying views regarding the importance of college culture and its role in achieving student satisfaction in the setting of educational institutions. Most importantly, most of the prior studies have assessed college culture from the perspective of employees. The present study differs from the prior studies by assessing college culture from the perspective of students. This approach of linking culture as perceived by students (customers) and students' (customers') satisfaction is expected to add a new discourse in the literature of organizational theory.

\section{Conceptual Framework for Understanding College Culture}

A number of researchers have shown that an organizational culture has a close link to the effectiveness of an organization (Denison, 1990; Kotter \& Heskett, 1992). In today's competitive environment, customer satisfaction is an increasingly important component of an effective organization, especially in the service sector (Berry \& Parasuraman, 1992; Farnell $\&$ Mithas, 2006). Education can be considered to be a part of service sector, within which colleges can be considered an organization providing service to its customers. In this case, students are consumers of services being offered by colleges. While consuming those services, students also become a part of college. It is evident from the fact that students represent their colleges to the world outside the college. They spend most of their time within colleges or working for college assignments and papers and in the process, we believe that students will build up their own understanding and perception of the college culture. So, in this study, we have assessed college culture as perceived by students, not as perceived by employees of the college.

The organizational culture framework used in the present study conceptualizes organizational culture along four dimensions: involvement, consistency, adaptability, and mission. A college high on adaptability dimension means it has the capacity to change in response to external condition. A college high on mission dimension means it knows why it exists and where it is heading. Similarly, high on involvement dimension means employees 
of the college are committed to their work, have a sense of ownership and feel that their input is valued. Similarly, a college high on consistency dimension means that there exist organizational system and process that promote alignment and efficiency.

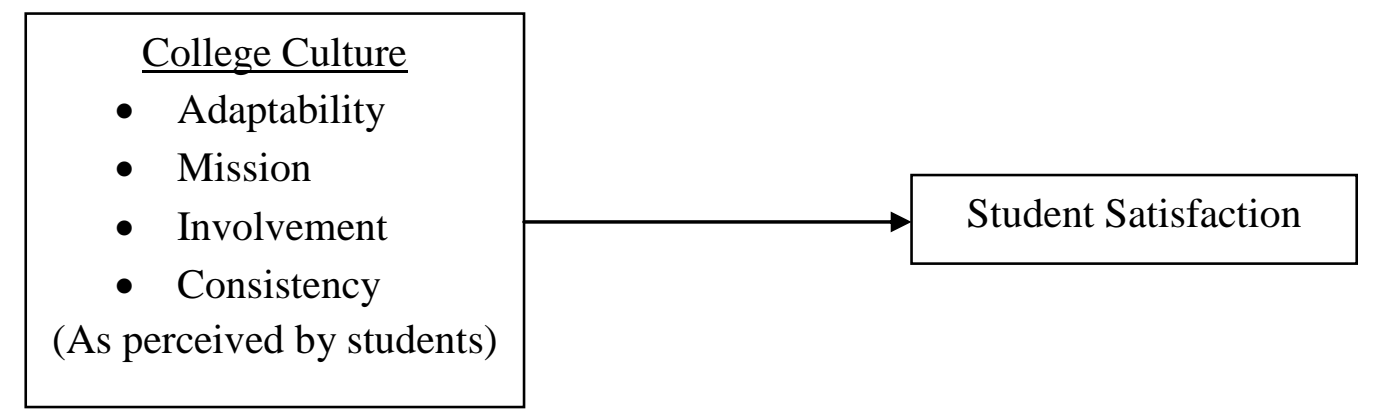

Figure 1. Conceptual framework of the study.

This conceptual framework of our study is based on the theory proposed by a grounded study of Denison and Mishra (1995). The theory was further empirically validated by a study conducted by Gillespie et al. (2007) on residential home building industry and automobile dealership.

\section{Hypothesis}

Basically deriving from Denison and Mishra (1995), we are of the view that each of four organizational cultural traits will relate to customer satisfaction. The trait of adaptability is related most obviously to customer satisfaction as it involves the capacity to respond to changing market demands.

H1: Adaptability perceived by students as a dimension of college culture is positively related with their satisfaction.

Gillespie et al. (2008) argued that "adaptability and mission when viewed together represent an external focus, which means organization's mission includes goals and strategies to meet customer demands" (pp. 118-119). Thus, mission will also be related to customer satisfaction.

$\mathrm{H} 2$ : Mission perceived by students as a dimension of college culture is positively related with their satisfaction.

Gillespie et al. (2008) further argued, "Traits of consistency and involvement are more internally focused. Through the focus on building shared values (consistency) and maintaining employee involvement, the organization is equipped to serve the needs of customer better in the long run" (p.119). Thus, we expected that organizations higher on the traits of consistency and involvement will have greater customer satisfaction.

H3: Involvement perceived by students as a dimension of college culture is positively related with their satisfaction. 
H4: Consistency perceived by students as a dimension of college culture is positively related with their satisfaction.

While we hypothesized that all four college culture traits should relate positively to student satisfaction, we also thought some of these traits might have stronger and some might have weaker relationship based on the logic used by Gillespie et al. (2008). As argued by Gillespie et al., adaptability is explicitly customer focused. Therefore it seems that adaptability is directly relevant to student satisfaction. Mission, together with adaptability, is externally focused. Therefore mission should be considered second to adaptability. Again as argued by Gillespie et al., involvement and consistency should demonstrate weaker relationship with customer satisfaction because these are internally focused characteristics. However, of those two, involvement should facilitate satisfying the customers by way of empowering employees. Consistency seems to oppose adaptability, the most customerfocused of the four traits. Thus, in line with the argument by Gillespie et al. (2008), we hypothesized that:

H5: The strengths of relationship of four college culture dimensions as perceived by students with student satisfaction will be in the following order from strongest to weakest: adaptability, mission, involvement, and consistency.

Okun et al. (1990) had assessed the effects of gender and grade level on student satisfaction. They found that grade level affects student satisfaction but gender had no effect. Although the study of Okun et al. was conducted among school students ranging from grade one to twelve, we are of the view that findings of the study will also be applicable to college students. So in accordance with the findings of Okun et al., we have assessed difference in student satisfaction level between groups based on gender and level in a study program (semester). Positive significant relationship between year in college and student satisfaction was also found by Bentz, Klingensmith, and Menne 1970, as cited in Liu \& Jung, 1980).

Bentz et al. (1970, as cited in Liu \& Jung, 1980) found that type of residence was also influential in affecting student satisfaction. In case of Nepal, the majority of colleges offering BBA program are concentrated within the Kathmandu valley. Some students in those colleges come from outside the valley. Staying away from their permanent residence and from other family members will mean they are barred from various kinds of family support which might affect their level of satisfaction with their colleges. So we have also assessed the difference in student satisfaction levels between groups based on whether the location of permanent residence of student is within the Kathmandu valley or outside the Kathmandu valley.

Universities currently offering the BBA program in Nepal differ in terms of various characteristics like - percentage of external and internal marks for each subject in the BBA program, holding exams as per the predefined academic calendar, timely publication of 
results. We are of the view that these university specific characteristics might also affect student satisfaction. So, we have also assessed the difference in student satisfaction levels between groups based on University affiliation.

\section{Methodology}

The population of this study comprised students enrolled in the BBA program in different colleges located in Kathmandu and Lalitpur districts. Moreover, the sampling consisted of two steps. In the first step, we prepared a list of all eligible colleges. The list was further stratified based upon University affiliation. There were 20 colleges affiliated to Pokhara University, 17 colleges affiliated to Tribhuvan University, 18 colleges affiliated to Purvanchal University, 4 colleges affiliated to Kathmandu University, and 9 colleges affiliated to different foreign universities. The number of students enrolled in the BBA program in each college was enquired to the administration of the respective colleges over the telephone. However, some colleges did not disclose the exact number of students. In such instances, an average of particular strata was used to calculate the total population. This way, the total number of students enrolled in the BBA program in the above mentioned colleges was estimated to be 11,314 for the year 2013. Thirty eight per cent of students of the total population were studying in colleges affiliated to Pokhara University, 22\% were in colleges affiliated to Tribhuvan University, $15 \%$ in colleges affiliated to Purvanchal University, 12\% in colleges affiliated to Kathmandu University, and 13\% in colleges affiliated to foreign universities. Based on our subjective decision, we distributed the questionnaires to ten colleges. Ten colleges were randomly selected from each stratum (university affiliation) to ensure the proportion of the sample to the population. Out of ten colleges, three were affiliated to Pokhara University, other three to Tribhuvan University, two to Purvanchal University, one to Kathmandu University, and one to a foreign university.

In the second step, based on our convenience we decided to distribute 30 sets of questionnaires to each of the ten selected colleges. Thus altogether 330 questionnaires were distributed but among them only 272 questionnaires were filled and returned. Out of them, 21 questionnaires were not completed, so we decided not to include them in further analysis. Thus, we used 251 data sets for further analysis. This happened to be 2.2 per cent of the estimated total student number studying BBA. Out of 251 data sets, $14.3 \%$ belonged to the students of Pokhara University, $46.6 \%$ to Tribhuvan University, $18.7 \%$ to Purvanchal University, $12.4 \%$ to Kathmandu University, and $8 \%$ to a foreign university. The proportion of universities being represented in the sample does not exactly match with that of the total population. This limitation of our study should be considered while interpreting the findings. Some of the students while responding to the questionnaire were in a hurry, so they might not have understood and internalized the meaning of each item prior to responding. This might have brought in some error and bias. This limitation should also be considered while interpreting the findings of this study. 
College culture as perceived by students was assessed by using the Denison Organizational Culture Survey (Denison \& Neale, 2000). The original survey consisted of 12 Likert scale items, 3 items per sub-scale. Each dimension was measured by a sub-scale. We conducted a pre-test of the survey among our probable respondents to ensure the clarity of instructions and question statements, and also conducted a reliability test of the sub-scales. Sub-scale measuring mission dimension had a Cronbach's alpha of 0.443 . The probable reason for low Cronbach's alpha for this sub scale is that students might not have been able to perceive strategy, goal, vision and mission of the college as well as employees could have. Given the low Cronhach's alpha, we dropped mission dimension of culture from the final survey. Cronbach's alphas for the subscales involvement, consistency and adaptability were found to be $0.718,0.605$, and 0.711 respectively. Seven Likert scale items were administered to measure student satisfaction. Out of the seven Likert scale items, three were adopted from the construct identified by Hartman and Schmidt (1995) to measure alumni satisfaction. Remaining four Likert scale items were developed and used by Silva and Fernandes (2012). Reliability test was conducted of these seven Likert scale items. Cronbach's alpha was found to be 0.773 . Both these instruments were incorporated in one set of questionnaires. In addition, the mean score was calculated for satisfaction and each dimension of culture. New variables were named avg_satisfaction, avg_involvement, avg_consistency, and avg_adaptability.

\section{Test of Normality}

Test of normality was conducted on the data set of dependent variable (avg_satisfaction) using Shapiro-Wilk test. Shapiro-Wilk test revealed p value to be 0.012 . Thus, we conclude that the data set is normally distributed at $1 \%$ significance level. The histogram of regression standardized residual of dependent variable indicates that the data set of dependent variable is normally distributed. Thus, we proceeded with the parametric test for further analysis.

\section{Findings of the Study}

The analysis of the survey data provided support on associations between different dimensions of college culture and student satisfaction. In line with this, we present the major findings of our study below.

\section{Correlation Between Students' Perceived Culture and Their Satisfaction}

Pearson correlation was used to determine the relation between culture dimensions as perceived by students and their satisfaction. As displayed in Table 1, the correlation between involvement dimension of culture and student satisfaction was 0.519 , consistency dimension of culture and student satisfaction was 0.437 , and adaptability dimension of culture and student satisfaction was 0.499 . All these correlations were significant at the 0.01 levels. 
Table 1

Scale Inter-correlation and Cronbach's Alpha

\begin{tabular}{llrrrrrr}
\hline & & Mean & SD & 1 & 2 & 3 & 4 \\
\hline 1 & Avg_Involvement & 3.16 & 0.95 & $(0.718)$ & & & \\
2 & Avg_Consistency & 3.27 & 0.79 & $.641^{* *}$ & $(0.604)$ & & \\
3 & Avg_Adaptability & 2.95 & 0.96 & $.592^{* *}$ & $.603^{* *}$ & $(0.711)$ & \\
4 & Avg_Satisfaction & 3.29 & 0.79 & $.519^{* *}$ & $.437^{* *}$ & $.499^{* *}$ & $(0.77)$ \\
\hline
\end{tabular}

**- Correlation is significant at the 0.01 level (2-tailed). Cronbach's alphas are provided in parentheses along the diagonal

This result supports our hypotheses H1, H3, and H4. Thus, we conclude the followings:

- Involvement perceived by students as a dimension of college culture is positively related with their satisfaction.

- Consistency perceived by students as a dimension of college culture is positively related with their satisfaction.

- Adaptability perceived by students as a dimension of college culture is positively related with their satisfaction.

\section{Dimensions of Culture and Student Satisfaction}

A regression analysis was conducted to determine the order of the strength of relationship of involvement, consistency, and adaptability with student satisfaction. The adjusted $\mathrm{R}$ square for the model is 0.320 , which means $32 \%$ of variation in student satisfaction is explained by independent variables of the regression model. F-statistics of the model is 39.824 and is significant at $1 \%$ significance level.

In a regression model that explains student satisfaction, unstandardized coefficient for constant is 1.573 , for avg_adaptability is 0.224 , for avg_involvement is 0.258 , and for avg_consistency is 0.076 (Table 2).

Table 2

Unstandardized Coefficients and Collinearity Statistics

\begin{tabular}{|c|c|c|c|c|}
\hline \multirow[b]{2}{*}{ Model } & \multicolumn{2}{|c|}{$\begin{array}{l}\text { Unstandardized } \\
\text { Coefficients }\end{array}$} & \multicolumn{2}{|c|}{$\begin{array}{c}\text { Collinearity } \\
\text { Statistics }\end{array}$} \\
\hline & B & $\begin{array}{l}\text { Std. } \\
\text { Error }\end{array}$ & Tolerance & VIF \\
\hline $1 \quad$ (Constant) & 1.573 & 0.181 & & \\
\hline Avg_Adaptability & 0.224 & 0.058 & 0.564 & 1.772 \\
\hline Avg_Involvement & 0.258 & 0.061 & 0.522 & 1.915 \\
\hline Avg_Consistency & 0.076 & 0.073 & 0.513 & 1.949 \\
\hline
\end{tabular}

a. Dependent Variable: Avg_Satisfaction

Journal of Education and Research, March 2014, Vol. 4, No. 1 
This does not support our hypothesized order of the strength of culture dimension with student satisfaction. Thus, based on the unstandardized coefficient of the regression model we conclude that the order of strength of relationship of college culture dimensions as perceived by students with student satisfaction will be in the following order from strongest to weakest: involvement, adaptability, and consistency.

\section{Difference in Satisfaction Levels Between Groups}

Difference in satisfaction level between two groups had been assessed by using independent sample t-test. The result of which is given in Table 3.

Table 3

Independent Sample t-test for Equality of Means Between Two Groups

\begin{tabular}{lccc}
\hline & $\begin{array}{c}\text { Equality of means } \\
\text { between* }\end{array}$ & T & $\begin{array}{c}\text { Sig. (2- } \\
\text { tailed) }\end{array}$ \\
\hline Avg_Satisfaction & Male / Female & -1.0631 & 0.2888 \\
\cline { 2 - 4 } & $\begin{array}{c}\text { Permanent resident } \\
\text { within/ outside } \\
\text { Kathmandu Valley }\end{array}$ & 0.9421 & 0.3471 \\
\hline
\end{tabular}

*- Equal variance not assumed

The $p$ value of $t$-statistics for both cases - male/female and permanent resident within/ outside the Kathmandu valley - is higher than 0.050. So we conclude that there is no statistically significant mean difference in satisfaction level between male and female; and between those with permanent resident within and outside the Kathmandu valley.

Difference in satisfaction level among various groups (in case of more than two groups) has been assessed by using one-way ANOVA test. In case of groups based on university, $p$ value of F-statistics is higher than 0.050 . So we conclude that there is no statistically significant mean difference in satisfaction level between groups based on university affiliation.

In case of groups based on semester, $p$ value of $F$-statistics is lower than 0.050 . So, we conclude that there is statistically significant mean difference in satisfaction level between groups based on semester. In the data set taken for analysis, one was from the first semester, 75 from the second semester, 30 from the third semester, 50 from the fourth semester, 34 from the fifth semester, 42 from the sixth semester, 18 from the seventh semester, and one from the eighth semester. Since two groups (i.e. first and eighth semester) have cases less than one, it was not possible to conduct post hoc test. In an effort to compensate unavailability of post hoc test results we drew a graph with semester in X-axis and mean of avg_satisfaction in Y-axis (Figure 2). 


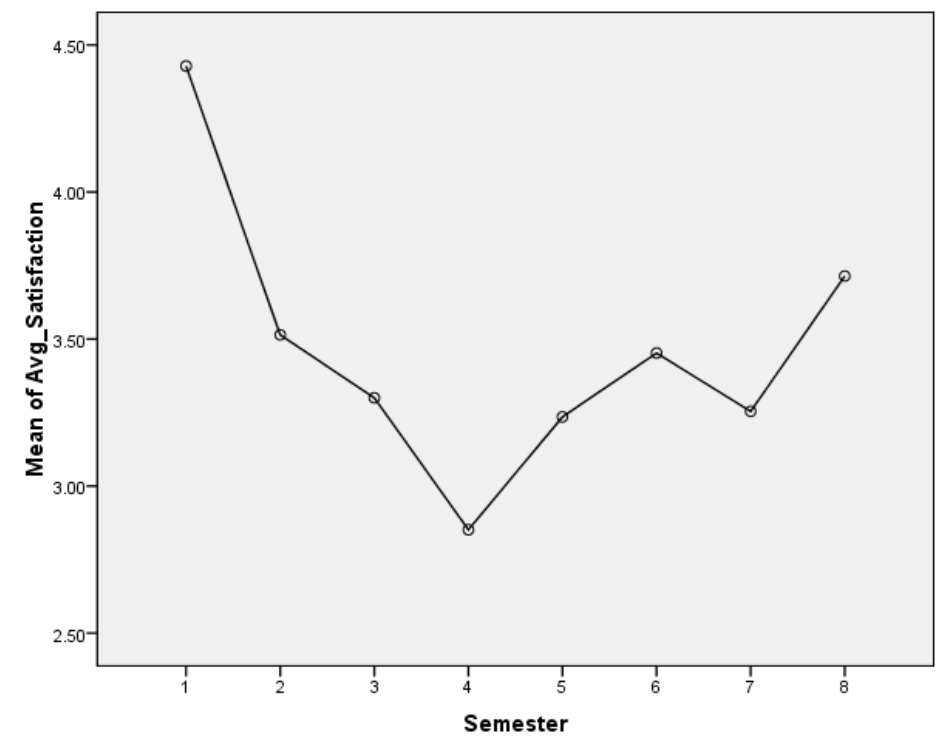

Figure 2. Mean of avg_satisfaction vs. semester.

As seen in Figure 2, the mean avg_satisfaction is lowest for the fourth semester students. However, we are not in a position to claim mean difference between which particular groups (based on semester) is statistically significant and between which particular groups are not statistically significant.

Our study also found no significant difference in satisfaction level between male and female students. This result is in congruence with the findings of many prior studies that have assessed relationship between student gender and satisfaction (e.g, Okun et al., 1990; Bellick, 1973, as cited in Liu \& Jung, 1990).

This study clearly indicates that 'involvement dimension of culture' (unstandardized beta coefficient $=0.258$ ) and 'adaptability dimension of culture' (unstandarized beta coefficient $=$ 0.224 ) are strongly associated; and 'consistency dimension of culture' (unstandarized beta coefficient $=0.076$ ) is moderately associated with student satisfaction. This implies that student satisfaction increases when the college invests in the development of employees, faculty and student skills; cooperation and team efforts from staff and students exist; and there is a sense of ownership and responsibilities towards the college. The relationship between 'adaptability dimension of culture' and student satisfaction is very understandable. As the college understands the need of students and adapts to the external environment, student satisfaction increases. Moreover, 'consistency dimension of college culture' is positively related to student satisfaction (correlation $=0.437$ ). However, the effect of 'consistency dimension of culture' on 'student satisfaction' is lower as compared to the effect of involvement and adaptability dimension. This indicates that students are willing to compromise on 'consistency' in lieu of 'having their say in things that affect them' (involvment). 
These findings are insightful to education practitioners of colleges offering the BBA program. Educational practitioners should make investments on their staff as well as students skills while creating an environment to work on common goal cooperatively and collectively. Students are more satisfied when they feel that they have some responsibilities and ownership towards their colleges as well. More specifically, this type of analysis of college culture as perceived by students and culture change effort as prescribed by this study will help Nepali colleges to attract and retain students in their BBA program. Students after spending few years in that institution become a part of that institution and develop an understanding of the culture within the institution and at the same time students pay for the services of that institution like that of a customer. Therefore, we can assume that students possess dual characteristics. Therefore, ignoring dual characteristic of students will limit the understanding of achievement of educational institution's effectiveness in terms of student attraction and retention.

\section{Organization Culture Matters Most in Educational Institution Settings}

The order of strength of relationship of college culture dimensions as perceived by students with student satisfaction predicted by our study rejects our prior hypotheses, and interestingly is not in congruence with the findings of a similar prior study. In a study of Gillespie et al. (2008), the order of the strength of relationship of culture dimension with customer satisfaction was in the following order from strongest to weakest: adaptability, consistency, involvement for home building industry; and for the auto dealership industry the ranking was in the order of consistency, involvement, adaptability. We think the most important reason for this difference is because of different industry type. The relationship between students and the college has different dynamics when compared with the relationship between home buyers and home building companies; and between auto buyers and auto dealers. On the other hand, the regression model of our study indicates that $32 \%$ of variation in response variable is explained by the explanatory variable. In case of other study with similar response variable and explanatory variables, only $17 \%$ and $8 \%$ variation in response variable is explained by the explanatory theory variable (Gillespie et al., 2008). This indicates that the relationship is stronger between culture and customer satisfaction in colleges than in other types of industries.

\section{Conclusion}

College culture plays an essential role in student satisfaction. Colleges that focus on the adaptability, involvement and consistency dimensions of culture are the ones that have satisfied students . Further, this study strengthens the argument that students of any higher educational institution after spending few years in that institution become a part of that institution and develop an understanding of the culture within the institution. Meanwhile, they also pay for the services offered by the institution so they also possess the characteristics of customers. Dual characteristics that students possess has been supported by this study which adds new discourse in the study of organization culture from the perspective of 
customers. A strong association between college culture dimensions and student satisfaction is an indication that education practitoners need to create a kind of culture within the institution that positively affects student satisfaction to achieve better organizational performance. Student satisfaction does hold a significant role in the success of educational institutions in a competitive environment. Thus, ignoring their perspectives towards the institution will only provide a partial understanding of why educational institutions suffer from student retention problem and low intake every year. Our study also found that Denison Organization Culture Model was applicable even in the context of Nepali higher educational institutions as the findings were in line with the result from previous studies, conducted in the western context, that used Denision Culture Model.

Some future studies are necessary in this area so as to strengthen the findings of this study in different contexts as well while including other performance variables in education institutions as profitability, employee satisfaction. A study with longitudinal design will further provide deeper insights into the understanding of college culture as perceived by students.

\section{References}

Barney, J. (1986). Organizational culture: Can it be a source of sustained competitive advantage? Academy of Management Review, 11, 656-665.

Berry, L., \& Parasuraman, A. (1992). Perception for service quality revolution in America. Organizational Dynamic, 20, 5-15.

Bentz, E. L., Klingensmith, J. E., \& Menne, J. W. (1970). The measurement and analysis of college student satisfaction. Measurement and Evaluation in Guidance, 3(2), 110-118.

Bitner, M., Booms, B., \& Mohr, L. (1994). Critical service encounters: The employee's viewpoint. Journal of Marketing, 58, 95-106.

Cameron, K., \& Quinn, R. (1999). Diagnosing and changing organizational culture. Reading, MA: Addison-Wesley.

Cameron, K., \& Quinn, R. (2006). Diagnosing and changing organizational culture: Based on the competing values framework (2nd ed.). San Francisco, CA: Jossey-Bass.

Carey, K., Cambiano, R. L., \& De Vore, J. B. (2002). Student to faculty satisfaction at a Midwestern university in the United States. HERDSA, 93-97.

Dangal, R. (2005). Administrative culture in Nepal: Does it reflect the dominant sociocultural values of Nepal? Bergen, Norway: University of Bergen.

Deal, T. E., \& Kennedy, A. A. (1982). Corporate cultures: The rites and rituals of corporate life. Reading, MA: Addison-Wesley.

Denison, D. (1990). Corporate culture and organizational effectiveness. New York, NY: John Wiley \& Sons.

Denison, D., \& Mishra, A. (1995). Toward a theory of organizational culture and effectiveness. Organization Science, 6(2), 204-223. 
Denison, D., \& Neale, W. (2000). Denison organizational culture survey. Ann Arbor, MI: Denison Consulting .

Deshpande, R., \& Farley, J. U. (2004). Organizational culture, market orientation, innovativeness and firm performance. International Journal of Research in Marketing, 22, 3-22.

Ehtesham, U., Muhammad, T., \& Muhammad, S. (2011). Relationship between organizational culture and performance management practices - A case of University of Pakistan. Journal of Competitiveness, 1(4), 78-86.

Farnell, C., \& Mithas, S. (2006). Customer satisfaction and stock prices: High returns, low risk. Journal of Marketing, 3-14.

Gillespie, M., Denison, D., Haaland, S., Smerek, R., \& Neale, W. (2008). Linking organizational culture and customer satisfaction: Results from two companies in different industries. European Journal of Work and Organizational Psychology,17(1), 112-132.

Hartman, D., \& Schmidt, S. (1995). Understanding student/alumni satisfaction from a consumer's perspective: The effect of institutional performance and program outcomes. Research in Higher Education, 36(2), 197-208.

Hasan, A., Ilias, A., Rahman, A., \& Razak, A. (2008). Service quality and student satisfaction: A case study at private higher education institutions. International Business Research, 1(3), 163-175.

Hom, W. (2002). Applying customer satisfaction theory to community college planning of student services. Retrieved from http://www.ijournal.us/issue_02/ij_issue02WillardHom _01.htm

Kotler, P., \& Clark, R. (1987). Marketing for health care organizations. Englewood Cliffs, NJ: Prentice-Hall.

Kotte, J., \& Heskett, J. (1992). Corporate culture and performance. New York, NY: The Free Press.

Levesque, T., \& McDougull, G. (1996). Determinants of customer satisfaction in retail banking. International Journal of Bank Marketing, 14(7), 12-20.

Liu, R., \& Jung, L. (1980). The commuters student and student satisfaction. Research in Higher Education, 12(3), 215-226.

Lund, D. (2003). Organizational culture and job satisfaction. Journal of Business and Industrial Marketing, 18(3), 219-236.

Martin, J. (1992). Cultures in organizations: Three perspectives. New York, NY: Oxford University Press.

Okun, M., Braver, M., \& Weir, R. (1990). Grade level differences in school satisfaction. Social Indicators Research, 22(4), 419-427.

Ouchi, W. G. (1981). Theory Z: How Americans business can meet the Japanese challenge. Boston, MA: Addison-Wesley.

Ouchi, W. (1980). Markets, bureaucracies, and clans. Administrative Science Quarterly, 25, 833-848.

Ouchi, W., \& Wilkins, A. (1985). Organizational culture. Annual Review of Sociology, 11, 457-483. 
Palacio, A. B., Meneses, G., \& Perez, P. P. (2002). The configuration of the university image and its relationship with the satisfaction of students. Journal of Educational Administration, 12(1), 486- 505.

Pant, D. (2007). Revolutionizing the mindsets: Roles and challanges for management development institutions in governance reform context. Administrative and Management Review, 19(2), 77-96.

Pascale, R., \& Athos, A. (1981). The art of Japanese management. New York, NY: Simon and Schuster.

Peters, T., \& Waterman, R., Jr. (1982). In search of excellence: Lessons from America's best run companies. New York, NY: Harper \& Row.

Porter, M. (1985). Competitive advantage. New York, NY: The Free Press.

Sathe, V. (1983). Implications of corporate culture: A manager's guide to action. Organizational Dynamics, 12(2), 4-23.

Schein, E. H. (1985). Organizational culture and leadership: A dynamic view. San Francisco,CA: Jossey-Bass.

Schein, E. H. (1983). Organization culture. Organizational Dynamics, 12, 13-28.

Schein, E. H. (1990). Organizational culture. American Psychologist, 45(2), 109-119.

Schueber, M. (2009). Understanding organizational culture in a development NGO in Nepal by applying academic theory to witnessed organizational behavior. Journal of Applied Anthropology, 495-515. Retrieved from http://www.omertaa.org/archive/omertaa0050.pdf

Shrestha, B. (2013). Public perception of the quality of academic education program. Journal of Education and Research,3(1), 52-64.

Silva, F., \& Fernandes, P. O. (2012). Empircal study on the student satisfaction in higher education: Importance-satisfaction analysis. World Academy of Science, Engineering and Technology, 6(6), 1192-1197.

Sin, L., \& Tse, A. (2000). How does marketing effectiveness mediate the effect of organizational culture on business performance? The case of service firms. Journals of Service Marketing, 14(4), 295-309.

Thapa, T. (2011). Total quality management in Nepal. A Multidisciplinary Journal,1(1), 8083.

Trice, H., \& Beyer, J. (1993). The culture of work organization. Upper Saddle River, NJ: Prentice Hall.

West-Moynes, M. L. (2012). A study of organizational culture in Ontario colleges with high student satisfaction. Toronto, Canada: Ontario Institute for Studies in Education.

William, J. (2002). The student satisfaction approach: Student feedback and its potential role in quality assessment and enhancement. Paper presented at the 24th EAIR Forum, 8-11 September, Prague, The Czech Republic. 